\title{
Development of Optical Biosensor Using Protein A-Conjugated Chitosan-Gold Nanoparticles for Diagnosis of Cystic Echinococcosis
}

\author{
Hanie Safarpour ${ }^{1,2}$, Hasan Majdi ${ }^{3,4}$, Ali Masjedi ${ }^{5,6}$, Abdol Sattar Pagheh ${ }^{7}$, Maria de Lourdes Pereira ${ }^{8,9, *}$, \\ Sonia M. Rodrigues Oliveira $8,10(1)$ and Ehsan Ahmadpour $1, *(\mathbb{C})$ \\ 1 Infectious and Tropical Disease Research Center, Tabriz University of Medical Sciences, \\ Tabriz 51666-14766, Iran; hanie.safarpour@yahoo.com \\ 2 Student Research Committee, Department of Parasitology and Mycology, Tabriz University of Medical \\ Sciences, Tabriz 51666-14766, Iran \\ 3 Drug Applied Research Center, Tabriz University of Medical Sciences, Tabriz 51666-14766, Iran; \\ hasan90majdi@yahoo.com \\ 4 Department of Medical Nanotechnology, Faculty of Advanced Medical Sciences, Tabriz University of Medical \\ Sciences, Tabriz 51666-14766, Iran \\ 5 Immunology Research Center, Tabriz University of Medical Sciences, Tabriz 51666-14766, Iran; \\ ali29masjedi@gmail.com \\ 6 Department of Immunology, Faculty of Medicine, Tabriz University of Medical Sciences, \\ Tabriz 51666-14766, Iran \\ 7 Infectious Diseases Research Center, Birjand University of Medical Sciences, Birjand 97178-53577, Iran; \\ satar2011@gmail.com \\ 8 CICECO-Aveiro Institute of Materials, University of Aveiro, 3810-193 Aveiro, Portugal; sonia.oliveira@ua.pt \\ 9 Department of Medical Sciences, University of Aveiro, 3810-193 Aveiro, Portugal \\ check for \\ updates \\ Citation: Safarpour, H.; Majdi, H.; \\ Masjedi, A.; Pagheh, A.S.; Pereira, \\ M.d.L.; Rodrigues Oliveira, S.M.; \\ 10 HMRI and Hunter Cancer Research Alliance Translational Cancer Research Centres, The University of \\ Newcastle, Callaghan, NSW 2308, Australia \\ * Correspondence: mlourdespereira@ua.pt (M.d.L.P.); ehsanahmadpour@gmail.com (E.A.); \\ Tel.: +351-234-378141 (M.d.L.P.); +98-413-5428595 (E.A.); Fax: +98-413-3373745 (E.A.)
} Ahmadpour, E. Development of Optical Biosensor Using Protein A-Conjugated Chitosan-Gold Nanoparticles for Diagnosis of Cystic Echinococcosis. Biosensors 2021, 11, 134. https://doi.org/10.3390/ bios11050134

Received: 28 February 2021

Accepted: 22 April 2021

Published: 25 April 2021

Publisher's Note: MDPI stays neutral with regard to jurisdictional claims in published maps and institutional affiliations.

Copyright: (c) 2021 by the authors. Licensee MDPI, Basel, Switzerland. This article is an open access article distributed under the terms and conditions of the Creative Commons Attribution (CC BY) license (https:// creativecommons.org/licenses/by/ $4.0 /)$.
Abstract: Human echinococcosis is a serious parasitic diseasethat still affects millions of people in many parts of the world. Since it can offer a critical threat to people's health, it is important to discover a rapid, convenient, and economical method for detection. Herein, we propose a novel point of care assay, namely, an enhanced immuno-dot-blot assay for diagnosis of cystic echinococcosis (hydatidosis). This method is based on the formation of a sandwich complex between a goldnanoprobe (chitosan-gold nanoparticleprotein A) and hydatid cyst antigen (Ag B), which holds anti-Ag B antibodies. Briefly, protein A was conjugated to chitosan-gold nanoparticles via glutaraldehyde chemistry. Then, Ag B was immobilized on the surface of a nitrocellulose membrane, which was followed by the addition of the sera sample and gold nanoprobes. The positive signals were easily detectable by naked eye. The signal intensity of this biosensor was proportional to the concentration of active anti-Echinococcus granulosus antibodies on the surface of the nanoparticles, titer of antibodies in the sera samples, and concentration of Ag B coated on the nitrocellulose membrane. The minimum concentration to use the protein A for conjugation to detect titer of anti-Echinococcus IgGand the concentration of Ag B coated in nitrocellulose membrane were 0.5 and $0.3 \mathrm{mg} / \mathrm{mL}$, respectively. This enhanced immuno-dot-blot assay offers a simple diagnostic technique withoutthe need for expensive equipment for diagnosis of echinococcosis.

Keywords: Echinococcus granulosus; hydatidosis; diagnosis; dot-blot; chitosan-gold nanoparticle; protein A; biosensor

\section{Introduction}

Cystic echinococcosis (CE) or hydatid disease is a chronic parasitic infection, which is listed among neglected tropical diseases and caused by the larval stage of Echinococcus 
granulosus (E. granulosus) [1]. Transmission of CE to humans occurs by accidental consumption of food or water contaminated with the parasite eggs. After the larvae enter the body, they form one or more cysts in internal organs, mainly in the liver and the lungs and, rarely, in the heart, spleen, kidneys, central nervous system, and bone [2,3]. The disease is widespread globally, with high endemicity in Central Asia, Mediterranean countries, Western China, South America, and Eastern Africa [4,5].

In most cases, the initial stages of infection is asymptomatic; even latent periods of more than 10 years have been reported [6]. Therefore, early detection at a lower cost is still needed for better clinical treatment and disease management. Diagnosis of CE is currently based on three factors: epidemiological history, imaging techniques (ultrasonography, magnetic resonance, and computerized tomography, etc.), and serological methods (indirect fluorescence antibody test (IFAT), enzyme-linked immunosorbent assay (ELISA), indirect hemagglutination (IHA), immunoelectrophoresis, and immunoblotting, etc.) $[7,8]$. Imaging methods are usually expensive, unavailable in less-developed, remote and secluded areas, and in some cases cannot differentiate between abscess and malignancy with the disease [9]. On the other hand, the conventional serological methods used for human CE diagnosis need specific equipment and expertise and are timeconsuming [10].

Optical biosensors can easily detect with the naked-eye the existence of pathogens in a sample without intricate requirements and analytical devices [11]. Several substances have been used to produce signals in optical biosensors (e.g., optical fiber with an enzyme, antibody, or nucleic acid), but gold nanomaterials are ideal reagents, due to their unique optical attributes [12].

Recently, the conjugation of nanoparticles (NPs) to proteins offers many applications in diagnosis methods $[13,14]$. Protein A (p.A) is a $42 \mathrm{kDa}$ cell surface protein that shows a high affinity for the $\mathrm{Fc}$-fragment of human IgG and IgGs from various other species [15]. Two different strategies are commonly used for conjugation of proteins to gold nanoparticles (GNPs): classic passive adsorption and covalent conjugation [16,17]. Passive adsorption has several drawbacks, such as desorption of the protein from the gold surface over time and possible impairment of necessary conformational changes required for the antigenbinding site [18]. Alternatively, covalent conjugation of proteins to GNPs minimizes many of the drawbacks. Use of functional polymers is a suitable way for the combination of a protein to GNPs, which along with immobilization and keeping the protein molecules on the surface, can also stabilize the GNPs colloidal suspension [19]. Chitosan (Chi), as a natural polymer polysaccharide (linear polysaccharide), contains hydroxyl and amine groups that can be used for immobilization of biomolecules [20]. Therefore, it has been used in GNPs coating for different biomedical applications. Recent studies have demonstrated the application of chitosan-gold nanoparticles (Chi-GNPs) for biomedical diagnosis. For example, antibody conjugated Chi-GNPs wereengineered for optical detection of Antigen $\operatorname{IgG}(\mathrm{Ag})$ in sandwich-like immunoassay systems [21]. In another study, Chi-GNPs were used for colorimetrical detection of Mycobacterium tuberculosis' nucleic acid via physical adsorption to Chi-GNPs [20]. However, up to now, there is no report of p.A conjugated Chi-GNPs for the detection of E. granulosus. In the present study, we propose a low-cost optical biosensor as a sensitive tool for the detection of $E$. granulosus.

\section{Method}

\subsection{Preparation of Hydatid Cysts Fluid}

Liver cysts of infected sheep were collected from a local slaughterhouse. The samples were processed in the laboratory and E. granulosus fertile cysts were sterilized with alcohol $70 \%$. The crude hydatid cysts fluid (HCF) was aseptically aspirated using a $10 \mathrm{~mL}$ syringe. In the next step, the HCF was centrifuged at $10,000 \times g$ for 30 min for separation of protoscolices (parasite larvae) from the supernatant. Finally, the supernatant was collected, and total protein content was determined via the Bradford assay and confirmed via SDSPAGE [22]. Samples were then stored at $-80^{\circ} \mathrm{C}$ until further use. 


\subsection{Preparation of Antigen $B$}

Antigen B (Ag B) was prepared from HCF based on the method previously described by Shirazi et al. (2016) [23]. In this method, $100 \mathrm{~mL}$ of HCF was centrifuged at $1500 \times g$ for $30 \mathrm{~min}$, and the supernatant was dialyzed twice with $0.005 \mathrm{M}$ acetate buffer $(\mathrm{pH}=5)$ for 24 $\mathrm{h}$ at $4{ }^{\circ} \mathrm{C}$. The dialyzed sample was centrifuged at $30,000 \times \mathrm{g}$ for $30 \mathrm{~min}$ at $4{ }^{\circ} \mathrm{C}$; this process allows insoluble proteins (Ag B and Ag 5) to settle. The pellet was dissolved in $10 \mathrm{~mL}$ of $0.2 \mathrm{M}$ phosphate buffer, $\mathrm{PBS}(\mathrm{pH}=8$ ) to eliminate globulins. Then, $2.31 \mathrm{~g}$ of ammonium sulfate $40 \%$ was added and mixed. After a short timeout, the mixture was centrifuged at $3000 \times g$ for $30 \mathrm{~min}$. The supernatant was incubated in a water bath for $15 \mathrm{~min}$; in this step, $\operatorname{Ag} 5$ became denatured and insoluble due to its heat sensitivity [24]. Finally, the preparation was centrifuged at 30,000 $\times g$ for $1 \mathrm{~h}$ and the supernatant containing $\mathrm{Ag}$ B was collected. Then, after filtration (using a $0.2 \mu \mathrm{m}$ sterile filter) sodium azide, $\mathrm{NaN}_{3}(\mathrm{x} \%, \mathrm{xM})$, was added as a preservative and the mixture was stored at $-80^{\circ} \mathrm{C}$.

\subsection{Synthesis of Chi-GNPs}

All required glassware was previously washed with distilled water and sonicated in an ultrasonic bath for $30 \mathrm{~min}$. For Chi-GNPs synthesis (Figure 1. Step I), $500 \mathrm{mg}$ of Chi (molecular weight, $50-190 \mathrm{kDa}, \mathrm{DD} \%$ 93\%, Sigma Aldrich) was dissolved in $50 \mathrm{~mL}$ of $1 \%$ $(v / v)$ aqueous solution of acetic acid (Merck), and the reaction was stirred at $65^{\circ} \mathrm{C}$ by thermostatic magnetic stirring. In the next step, $50 \mathrm{~mL}$ of $\mathrm{HAuCl}_{4}(1 \mathrm{mmol} / \mathrm{L}$ tetrachloroauric acid) solution was added to the reaction and kept at $65^{\circ} \mathrm{C}$ for $2 \mathrm{~h}$ until the color turned wine red. The reaction solution was stirred overnight at $65^{\circ} \mathrm{C}$. The synthesized Chi-GNPs were analyzed using UV-vis spectroscopy. Determination of particle size and zeta potential of the Chi-GNPs were performed by a dynamic light scattering (DLS) instrument (Malvern Zetasizer). Finally, field emission scanning electron microscopy (FE-SEM) studied the Chi-GNPs morphology.

\subsection{Bio-Conjugation of Protein A on Chi-GNPs Surface}

In the present study, we utilized glutaraldehyde (GA) for conjugating p.A with the surface of the Chi-GNPs. The functional aldehyde groups of the GA readily combine with the amine groups of Chi layer on the surface of GNPs. In the first stage, the solution of Chi-GNPs was diluted in distilled water at room temperature, and the $\mathrm{pH}$ adjusted to 5.5 . Next, $2 \%$ GA was added to the nanoparticles' solution (GA-Chi-GNPs), and left to incubate for $2 \mathrm{~h}$ at $40^{\circ} \mathrm{C}$. Then, the mixture was washed three times with $0.01 \mathrm{M}$ PBS (pH 7.4) by centrifugation to eliminate the residual GA. In the next step, $0.3 \mathrm{~mL}$ of p.A $(1 \mathrm{mg} / \mathrm{mL})$ was combined with $0.7 \mathrm{~mL}$ of GA-Chi-GNPs solution and incubated for $24 \mathrm{~h}$ at $4{ }^{\circ} \mathrm{C}$. Following, the solution was washed again three times with PBS; then, it was incubated with BSA (5\%) in PBS (0.01 M, pH 8.5) for $45 \mathrm{~min}$ at $20^{\circ} \mathrm{C}$ to prevent non-specific binds on the surface of the nanoparticles. In the final step, the conjugate was washed three times with $0.01 \mathrm{M}$ PBS ( $\mathrm{pH}$ 7.4) to remove physical adsorptions, and then, re-suspended in PBS and stored at $4{ }^{\circ} \mathrm{C}$ until further testing (Figure 1, Step II).

\subsection{Colorimetric Detection}

As a control, $0.4 \mathrm{~mL}$ p.A-Chi-GNPs and $0.2 \mathrm{~mL}$ of PBS ( $\mathrm{pH}=7.4)$ were combined and incubated for $20 \mathrm{~min}$ at room temperature, then UV-Vis spectra was recorded over the wavelength in the range of $400-800 \mathrm{~nm}$. In the experiment sample, $0.2 \mathrm{~mL}$ of human anti-Echinococcus IgG solution $(1 \mathrm{mg} / \mathrm{mL})$ was added to the $0.4 \mathrm{~mL}$ p.A-Chi-GNPs and incubated for $20 \mathrm{~min}$ at $25^{\circ} \mathrm{C}$, then UV-Vis absorption spectra was recorded in the wavelength range mentioned in the control.

\subsection{Dot-Blot Assay}

An aliquot of $1 \mu \mathrm{L}$ of each $\mathrm{Ag} B$ solution $(1.2,0.6$, and $0.3 \mathrm{mg} / \mathrm{mL})$ was spotted on the center of each chamber in nitrocellulose membrane (NC) and allowed to dry for $30 \mathrm{~min}$ at $25{ }^{\circ} \mathrm{C}$. Then, membranes were blocked with BSA solution $(5 \% w / v)$ and air-dried for 
$1 \mathrm{~h}$ to avoid non-specific binding with the membrane, then washed three times with PBS. In the next step, membranes were incubated with anti-Echinococcus IgG (1:1, 1:10 and, 1:100 dilutions) for $1 \mathrm{~h}$ at $25^{\circ} \mathrm{C}$ and then washed as described before. Finally, membranes were incubated with p.A-Chi-GNPs for $20 \mathrm{~min}$, washed three times with PBS, and dried at room temperature (Figure 1, Step III). At the end, optical results were recorded with a common camera. The numbers of Toxoplasma gondii (T. gondii) positive sera were used to test for cross-reactivity.

Step I: Synthesis of chitosan coated gold nanoparticle

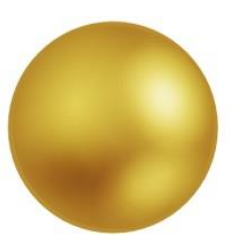

AuNP

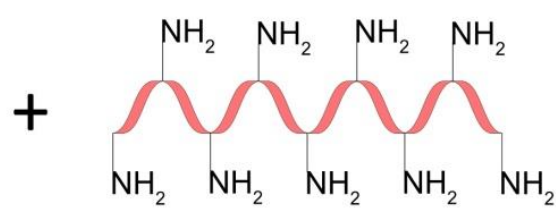

Chitosan (Chi)

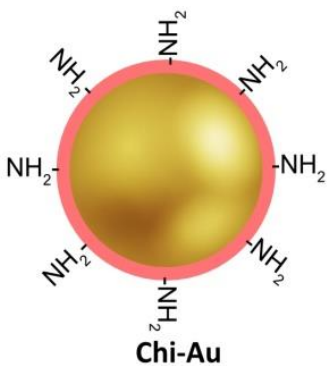

Step II: Bio-conjugation of protein-A to Chi-Au

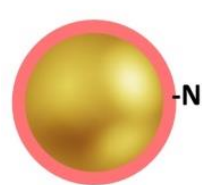

Chi-Au<smiles>N[I+]C(=O)CCCC(=O)C1CCCC1</smiles>

Glutaraldehyde(GA)

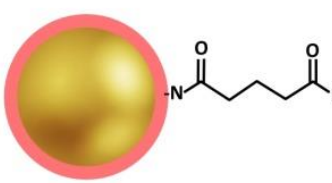

Chi-Au-GA

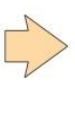

Chi-Au

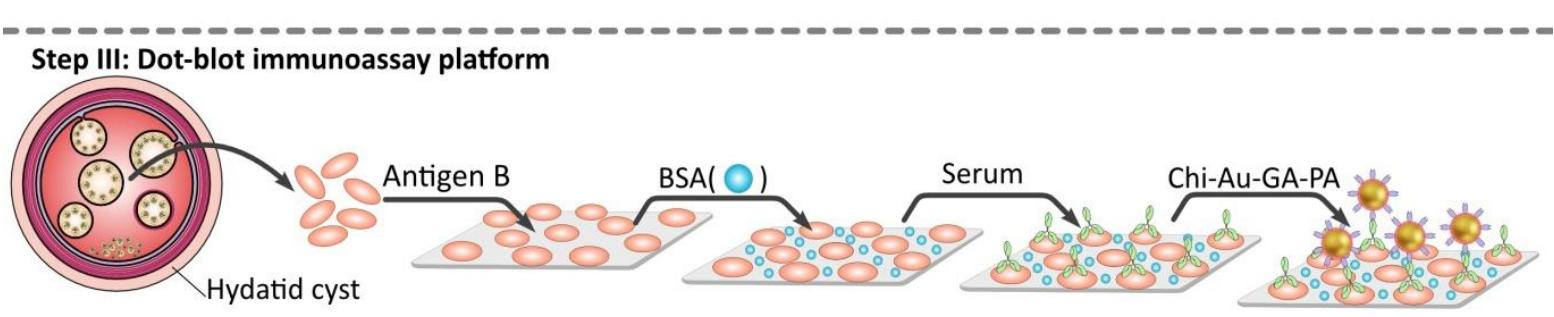

Figure 1. Synthesis of the chitosan-gold nanoparticles followed by complexation with Protein A for sandwich-based E. granulosus biosensor. Step I: Colloid gold nanoparticles were synthesized using chitosan. Step II: Chi-GNPs surface was activated by GA and conjugated with proteinA. Step III: Hydatid cyst antigen (Ag B) was immobilized on the NC membrane, membranes were blocked with BSA, and then, treated with serum sample, and finally, each sample was dipped into Chi-GNPs-GA-P.A conjugate.

\section{Results}

\subsection{SDS-PAGE Purified Ag B Characterization}

$\mathrm{Ag} B$ was successfully isolated, and its total concentration was measured by Bradford assay. The protein concentration of Ag B was $1.2 \mathrm{mg} / \mathrm{mL}$. SDS-PAGE analysis showed bands on 20 and $24 \mathrm{KDa}$ subunits of $\mathrm{Ag} \mathrm{B}$ (data not shown).

\subsection{Characterization of the Colloidal Chi-GNPs}

Colloidal Chi-GNPs solution appears wine red color and the UV-Vis spectrum of Chi-GNPs showed maximum absorption at $522 \mathrm{~nm}$. SEM imaging confirmed that shape and size distribution of Chi-GNPs were slightly homogeneous and non-aggregated with smooth surfaces (Figure 2A). The particle size distribution histogram determined by the SEM images indicated that particles are in the range of 13-27 nm with average diameter size of $19.95 \mathrm{~nm}$ (Figure 2B). Chi-GNPs showed an average hydrodynamic diameter of $41.6 \mathrm{~nm}$ with a polydispersity index (PDI) of 0.3 and zeta potential of $35.6 \mathrm{mV}$ determined by Zetasizer (Figure 2C). 

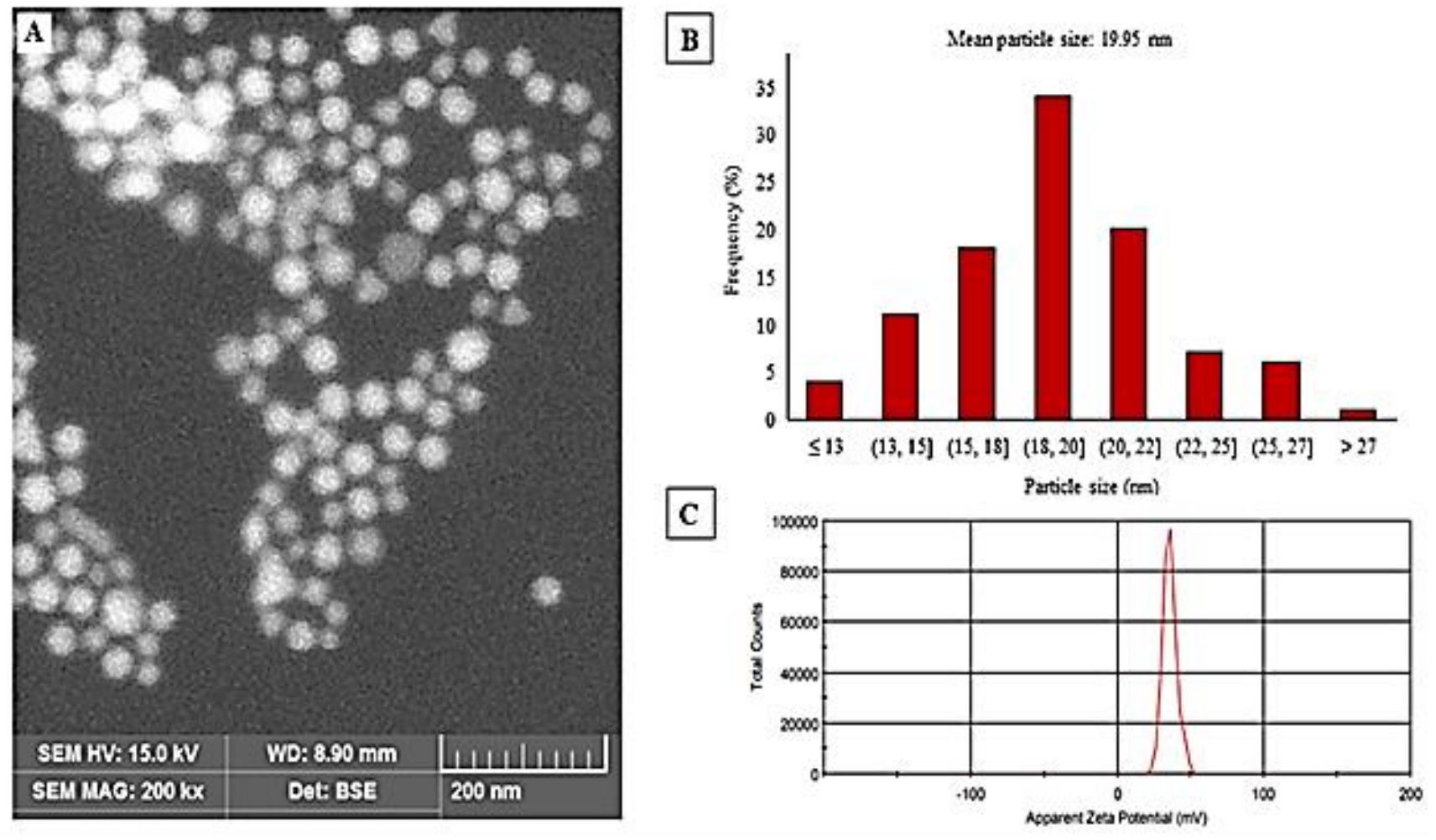

Figure 2. (A): SEM image, (B): SEM size distribution histogram, and (C): Zeta potential of Chi-GNPs.

\subsection{Conjugation and Characterization of Protein A-Chi-GNPS}

We also demonstrate that using of GA for the conjugation of p.A on Chi-GNPs surface resulted in good stability of the Chi-GNPs. In order to find the optimum amount of p.A, different concentrations of $0.25,0.5$, and $1 \mathrm{mg} / \mathrm{mL}$ of this protein were used for conjugation on colloidal Chi-GNPs surface. Indeed, by raising p.A concentration, the stability of Chi-GNPs was increased. The UV/Vis spectra of the Chi-GNPs and p.A-Chi-GNPs showed $4 \mathrm{~nm}$ shifts in the SPR peak after the conjugation of p.A on Chi-GNPs layer. The conjugation of the p.A on colloidal GNPs can be effectuated a shift from 529 to $532 \mathrm{~nm}$. In addition, HRP protein was used to verify the conjugation of p.A on the Chi-GNPs' surface. HRP-Tagged-human IgG and HRP-Tagged-human IgM were added to the p.A-Chi-GNPs solution as control. After the addition of substrate (TMB), the blue color appearance of the solution in the presence of HRP-Tagged-human IgG confirmed that the protein- conjugated Chi-GNPs wereactive.

\subsection{Dot-Blot Immunoassay}

The principle of this method using dual labeled GNPs (Chi-AuNP-p.A) is based on indirect sandwich of immuno-dot-blot assay (Figure 3). Two concentrations of p.A coupled Chi-GNPs were applied to detect anti-E. granulosus antibodies. The color appearance was correlated with the concentration of p.A. The results show that the lowest concentration of anti-E. granulosus antibodies can be detected with the $0.5 \mathrm{mg} / \mathrm{mL}$ concentration of p.A-coupled Chi-GNPs, in the serum samples. In view of that, this biosensor effectively detected the 1:100 dilution of the anti-Echinococcus IgG in $0.3 \mathrm{mg} / \mathrm{mL}$ of Ag B. The color intensity decreased with the decline of $\mathrm{Ag} B$ concentration. In contrast, there was no color observed in the negative controls. The specificity, efficiency, and the limit of detection were analyzed under the optimum reaction conditions. Three concentrations, $0.3,0.6$, and $1.2 \mathrm{mg} / \mathrm{mL}$, of Ag B spotted in NC membrane and a non-specific antigen T. gondii and PBS were used as negative controls. It revealed that the GNPs-based biosensor is able to visually detect a minimal concentration of anti-Echinococcus antibodies in real samples. 
I

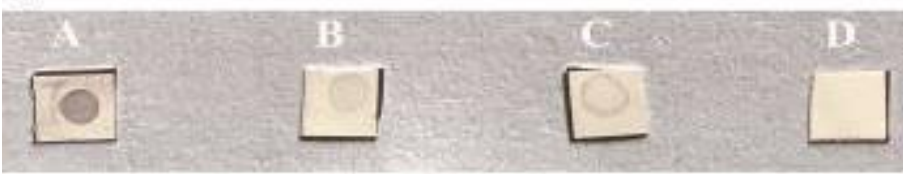

II

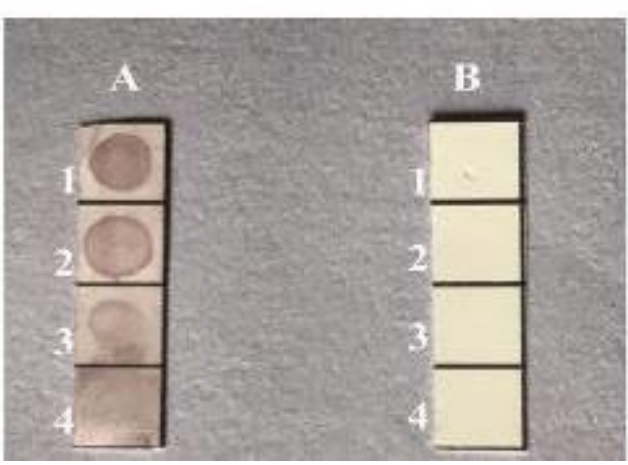

Figure 3. Image of dot-blot immunoassay by $0.5 \mathrm{mg} / \mathrm{mL}$ concentration of conjugated p.A on Chi-GNPs surface for detection of antibody at various dilutions. (I): (A): anti-Echinococcus IgG 1:1, (B): anti-Echinococcus IgG 1:10, (C): anti-Echinococcus IgG 1:100, (D): control. (II): (A): Ag B, 1:1.2 mg/mL, 2:0.6 mg/mL, 3:0.3 mg/mL, 4:0.15 mg/mL. (B): Control.

\section{Discussion}

Echinococcosis is a neglected serious parasitic disease that affects millions of individuals worldwide and manifests devastating effects on animal husbandry. Recent studies highlighted on various aspects of E. granulosus such as world distribution, pathogenesis, diagnostic methods, and novel therapeutic in humans and animals [1,25]. Although there are various methods for diagnosis of this zoonosis parasite, many of these tests requirespecialist training and strict infrastructure demands, with a relativelyhighcost. Among the common methods, the imagining techniques are used to screen the population at a relatively inexpensive cost, such asultrasonography and radiology (X-ray) [1]. Furthermore, the serology tests are also widely used for detection of markers from the parasite (circulating antigens or DNA) and from the host (markers of inflammation, cytokines, or chemokines) $[9,26]$. Today, clinicians can follow specific guides and algorithms for the diagnosis and treatment of echinococcosis $[1,27]$. The laboratory diagnosis of cystic echinococcosis (CE) includes, among others, the detection of antibodies, antigens, and cytokines. However, these approaches are not ideal as valid diagnostic tools, given the lack of sensitivity and/or sufficient specificity [28]. Moreover, they require specific infrastructure settings and trained personnel.

Currently, with the advent of nanotechnology, a great advance has been possible in the development of biosensors for the diagnosis of echinococcosis. Li et al. (2017) [29] reported on an optical biosensor for the detection of cystic hydatid disease based on the near-infrared transmission angular spectra of porous silicon microcavity, as a useful method. More recently, in silico design and evaluation was reported as a suitable method of hydatid cyst antigens diagnosis [30]. Notably, researchers have been developing portable electroanalytical biosensing analyzers or devices, in order to efficiently, effectively, and quickly detect pathogens. Despite substantial progress in recent years, more simple and fast techniques are still needed urgently. Thus, nanoparticle-based biosensors are highlydesirablefor their chemical and mechanical properties, which have capabilities in human and veterinary medicine [31,32].

The present study proposes a simple, fast, and advantageous method for the diagnosis of echinococcosis. This method is based on the formation of a sandwich complex between a goldnanoprobe (chitosan-gold nanoparticleprotein $\mathrm{A}$ ) and hydatid cyst antigen (Ag B), which holds anti-Ag B antibodies. The colorimetric results are achieved fast by visual a change in colors, which remain unchanged upon the negative presence of $\mathrm{Ag} B$ 
antibodies. It is noteworthy that we present a field-applicable method based on a blood sample for rapid diagnosis of infected cases, without needingto expert individuals and advanced equipment.

It is also well demonstrated that gold nanoprobes have been widely used for biosensing, particularly via DNA detection. In an elegant study, a multiplex non-cross-linking colorimetric methodology approach was used for detection of malaria and tuberculosis pathogens [33]. Our research in this direction has given fruitful results, by using chitosangold nanoparticles protein $\mathrm{A}$ and $\mathrm{Ag} \mathrm{B}$. This novel colorimetric biosensor approach was demonstrated to quickly and effectively detect $E$. granulosus infection. Chitosan has been previously used to optimize the synthesis of gold nanoparticles and to develop distinct color changes [34]. Chitosan-capped gold nanoparticles or gold nanoparticles functionalized or stabilized with organic polymers such as chitosan nanocomposites have been described as optimal delivery systems, avoiding the toxicity inherent to other chemicals reagents $[35,36]$.

To summarize, we described here for the first time a fast, stable, and cost-effective biosensor with a colorimetric reading for detecting E. granulosus infections. In fact, chitosanbased biosensors have reported good selectivity, sensitivity, and stability for the detection of various targets including glucose, proteins, DNAs, bacteria, and several small biomolecules [37,38]. Remarkably, colorimetric biosensors and gold nanoparticle colorimetric biosensors have shown significant applications in diagnostics [39,40]. Here, we gathered the current knowledge in nanotechnology and colorimetric biosensors to develop this novel Echinococcosis biosensor that can help clinicians and professionals in the field for screening populations and quickly address potential epidemic focus.

\section{Conclusions}

As a conclusion, the GNPs (or AuNPs)-based biosensor was designed for visual detection of minimal concentration of anti-Echinococcus IgG in human and animal blood samples for the diagnosis of cystic echinococcosis. In the future, simple and affordable biosensors will be in high demand, as their possible in situ applications will be very important for screening and controlling epidemic and pandemic situations. These portable devices will be particularly valuable where strictly controlled infrastructures are not accessible or possible. The proof-of-concept here described and characterized may easily translate into practical settings that allow fast and simple Au-nanoprobe-based detection on-demand.

Author Contributions: Conceptualization, E.A., A.S.P. and M.d.L.P.; methodology, H.S., E.A., H.M., and A.M.; validation, A.S.P., S.M.R.O. and M.d.L.P.; investigation, H.S., H.M. and A.M.; data curation, E.A. and M.d.L.P.; writing — original draft preparation, H.S., H.M., A.M., A.S.P. and S.M.R.O.; writingreview and editing, E.A. and M.d.L.P. All authors have read and agreed to the published version of the manuscript.

Funding: This study was funded by Infectious and Tropical Diseases Research Center, Tabriz University of Medical Sciences, Tabriz, Iran (Grant No. 63205). M.d.L.P. thanks Project CICECO-Aveiro Institute of Materials, UIDB/50011/2020 and UIDP/50011/2020, national funds by the Portuguese Foundation for Science and Technology/MCTES.

Institutional Review Board Statement: All experiments were approved by the local Ethics Committee of Tabriz University of Medical Sciences, Tabriz, Iran (No. IR.TBZMED.REC.1398.128).

Data Availability Statement: Not applicable.

Conflicts of Interest: The authors declare no conflict of interest.

\section{References}

1. Wen, H.; Vuitton, L.; Tuxun, T.; Li, J.; Vuitton, D.A.; Zhang, W.; McManus, D.P. Echinococcosis: Advances in the 21st century. Clin. Microbiol. Rev. 2019, 32. [CrossRef] [PubMed]

2. Moro, P.; Schantz, P.M. Echinococcosis: A review. Int. J. Infect. Dis. 2009, 13, 125-133. [CrossRef]

3. Craig, P.S.; McManus, D.P.; Lightowlers, M.W.; Chabalgoity, J.A.; Garcia, H.H.; Gavidia, C.M.; Gilman, R.H.; Gonzalez, A.E.; Lorca, M.; Naquira, C. Prevention and control of cystic echinococcosis. Lancet Infect. Dis. 2007, 7, 385-394. [CrossRef] 
4. Deplazes, P.; Rinaldi, L.; Rojas, C.A.; Torgerson, P.; Harandi, M.; Romig, T.; Antolova, D.; Schurer, J.; Lahmar, S.; Cringoli, G. Global distribution of alveolar and cystic echinococcosis. In Advances in Parasitology; Elsevier: Amsterdam, The Netherlands, 2017; Volume 95, pp. 315-493.

5. Galeh, T.M.; Spotin, A.; Mahami-Oskouei, M.; Carmena, D.; Rahimi, M.T.; Barac, A.; Ghoyounchi, R.; Berahmat, R.; Ahmadpour, E. The seroprevalence rate and population genetic structure of human cystic echinococcosis in the Middle East: A systematic review and meta-analysis. Int. J. Surg. 2018, 51, 39-48. [CrossRef]

6. Frider, B.; Larrieu, E.; Odriozola, M. Long-term outcome of asymptomatic liver hydatidosis. J. Hepatol. 1999, 30, $228-231$. [CrossRef]

7. Zhang, W.; Wen, H.; Li, J.; Lin, R.; McManus, D.P. Immunology and immunodiagnosis of cystic echinococcosis: An update. Clin. Dev. Immunol. 2011, 2012, 101895. [CrossRef]

8. Kern, P. Echinococcus granulosus infection: Clinical presentation, medical treatment and outcome. Langenbecks Arch. Surg. 2003, 388, 413-420. [CrossRef]

9. McManus, D.P.; Gray, D.J.; Zhang, W.; Yang, Y. Diagnosis, treatment, and management of echinococcosis. BMJ 2012, 344 , e3866. [CrossRef]

10. Manzano-Román, R.; Sánchez-Ovejero, C.; Hernández-González, A.; Casulli, A.; Siles-Lucas, M. Serological diagnosis and follow-up of human cystic echinococcosis: A new hope for the future? BioMed Res. Int. 2015, 2015, 428205. [CrossRef]

11. Yoo, S.M.; Lee, S.Y. Optical biosensors for the detection of pathogenic microorganisms. Trends Biotechnol. 2016, 34, 7-25. [CrossRef]

12. Fan, X.; White, I.M.; Shopova, S.I.; Zhu, H.; Suter, J.D.; Sun, Y. Sensitive optical biosensors for unlabeled targets: A review. Anal. Chim. Acta 2008, 620, 8-26. [CrossRef]

13. De, M.; Rana, S.; Akpinar, H.; Miranda, O.R.; Arvizo, R.R.; Bunz, U.H.; Rotello, V.M. Sensing of proteins in human serum using conjugates of nanoparticles and green fluorescent protein. Nature Chem. 2009, 1, 461. [CrossRef]

14. Willner, I.; Baron, R.; Willner, B. Integrated nanoparticle-biomolecule systems for biosensing and bioelectronics. Biosens. Bioelectron. 2007, 22, 1841-1852. [CrossRef]

15. Hober, S.; Nord, K.; Linhult, M. Protein A chromatography for antibody purification. J. Chromatogr. B 2007, 848, 40-47. [CrossRef]

16. Geoghegan, W.D.; Ackerman, G.A. Adsorption of horseradish peroxidase, ovomucoid and anti-immunoglobulin to colloidal gold for the indirect detection of concanavalin A, wheat germ agglutinin and goat anti-human immunoglobulin $\mathrm{G}$ on cell surfaces at the electron microscopic level: A new method, theory and application. J. Histochem. Cytochem. 1977, 25, 1187-1200.

17. Büchel, C.; Morris, E.; Orlova, E.; Barber, J. Localisation of the PsbH subunit in photosystem II: A new approach using labelling of His-tags with a Ni2+-NTA gold cluster and single particle analysis. J. Mol. Biol. 2001, 312, 371-379. [CrossRef]

18. Aubin-Tam, M.-E. Conjugation of nanoparticles to proteins. In Nanomaterial Interfaces in Biology; Springer: Berlin/Heidelberg, Germany, 2013; pp. 19-27.

19. Marega, R.; Karmani, L.; Flamant, L.; Nageswaran, P.G.; Valembois, V.; Masereel, B.; Feron, O.; Vander Borght, T.; Lucas, S.; Michiels, C. Antibody-functionalized polymer-coated gold nanoparticles targeting cancer cells: An in vitro and in vivo study. $J$. Mater. Chem. 2012, 22, 21305-21312. [CrossRef]

20. Karthikeyan, R.; Berchmans, S.; Chandran, S.; Pal, P. Functionalization of electrochemically deposited chitosan films with alginate and Prussian blue for enhanced performance of microbial fuel cells. Electrochim. Acta 2013, 112, 465-472.

21. Majdi, H.; Salehi, R.; Pourhassan-Moghaddam, M.; Mahmoodi, S.; Poursalehi, Z.; Vasilescu, S. Antibody conjugated green synthesized chitosan-gold nanoparticles for optical biosensing. Colloid Interface Sci. Commun. 2019, 33, 100207. [CrossRef]

22. Rafiei, A.; Jahanshahi, A.; Talaeizadeh, A. Evaluation of specific IgG antibody detection in diagnosis and post surgical monitoring of cystic echinococcosis. Iran. J. Parasitol. 2008, 3, 10-14.

23. Shirazi, S.; Madani, R.; Hoghooghi Rad, N.; Ranjbar Bahadori, S. Isolation and purification of Echinococcus granulosus antigen B from hydatid cyst fluid using three different methods. Arch. Razi Inst. 2016, 71, 103-108.

24. Oriol, R.; Williams, J.; Esandi, M.V.P.; Oriol, C. Purification of lipoprotein antigens of Echinococcus granulosus from sheep hydatid fluid. Am. J. Trop. Med. Hyg. 1971, 20, 569-574. [CrossRef]

25. Eckert, J.; Thompson, R.C.A. Chapter One-Historical Aspects of Echinococcosis. In Advances in Parasitology; Thompson, R.C.A., Deplazes, P., Lymbery, A.J., Eds.; Academic Press: Cambridge, MA, USA, 2017; Volume 95, pp. 1-64.

26. Gottstein, B.; Wang, J.; Blagosklonov, O.; Grenouillet, F.; Millon, L.; Vuitton, D.A.; Müller, N. Echinococcus metacestode: In search of viability markers. Parasite 2014, 21, 63. [CrossRef]

27. Brunetti, E.; Kern, P.; Vuitton, D.A.; Vuitton, D.A. Expert consensus for the diagnosis and treatment of cystic and alveolar echinococcosis in humans. Acta Trop. 2010, 114, 1-16. [CrossRef]

28. Siles-Lucas, M.; Casulli, A.; Conraths, F.J.; Müller, N. Chapter Three-Laboratory Diagnosis of Echinococcus spp. in Human Patients and Infected Animals. In Advances in Parasitology; Thompson, R.C.A., Deplazes, P., Lymbery, A.J., Eds.; Academic Press: Cambridge, MA, USA, 2017; Volume 96, pp. 159-257.

29. Li, P.; Jia, Z.; Lü, G. Hydatid detection using the near-infrared transmission angular spectra of porous silicon microcavity biosensors. Sci. Rep. 2017, 7, 44798. [CrossRef]

30. Darabi, E.; Motevaseli, E.; Khorramizadeh, M.R.; Mohebali, M.; Rokni, M.B.; Zahabiun, F.; Kia, E.B. Design and Construction of a Fusion Peptide Containing B1, B2, B4, and EPC1 Epitopes for Diagnosis of Human Cystic Echinococcosis. Iran. J. Public Health 2019, 48, 1671-1680. [CrossRef]

31. Cesewski, E.; Johnson, B.N. Electrochemical biosensors for pathogen detection. Biosens. Bioelectron. 2020, 159, 112214. [CrossRef] 
32. Moulick, A.; Richtera, L.; Milosavljevic, V.; Cernei, N.; Haddad, Y.; Zitka, O.; Kopel, P.; Heger, Z.; Adam, V. Advanced nanotechnologies in avian influenza: Current status and future trends-A review. Anal. Chim. Acta 2017, 983, 42-53. [CrossRef]

33. Veigas, B.; Pedrosa, P.; Carlos, F.F.; Mancio-Silva, L.; Grosso, A.R.; Fortunato, E.; Mota, M.M.; Baptista, P.V. One nanoprobe, two pathogens: Gold nanoprobes multiplexing for point-of-care. J. Nanobiotechnol. 2015, 13, 48. [CrossRef]

34. Mohan, C.O.; Gunasekaran, S.; Ravishankar, C.N. Chitosan-capped gold nanoparticles for indicating temperature abuse in frozen stored products. NPJ Sci. Food 2019, 3, 2. [CrossRef] [PubMed]

35. Abrica-Gonzalez, P.; Zamora-Justo, J.A.; Sotelo-Lopez, A.; Vazquez-Martinez, G.R.; Balderas-Lopez, J.A.; Munoz-Diosdado, A.; Ibanez-Hernandez, M. Gold nanoparticles with chitosan, N-acylated chitosan, and chitosan oligosaccharide as DNA carriers. Nanoscale Res. Lett. 2019, 14, 258. [CrossRef] [PubMed]

36. Saeed, R.M.; Dmour, I.; Taha, M.O. Stable Chitosan-Based Nanoparticles Using Polyphosphoric Acid or Hexametaphosphate for Tandem Ionotropic/Covalent Crosslinking and Subsequent Investigation as Novel Vehicles for Drug Delivery. Front. Bioeng. Biotechnol. 2020, 8. [CrossRef] [PubMed]

37. Jiang, Y.; Wu, J. Recent development in chitosan nanocomposites for surface-based biosensor applications. Electrophoresis 2019, 40, 2084-2097. [CrossRef]

38. Shrestha, B.K.; Ahmad, R.; Mousa, H.M.; Kim, I.-G.; Kim, J.I.; Neupane, M.P.; Park, C.H.; Kim, C.S. High-performance glucose biosensor based on chitosan-glucose oxidase immobilized polypyrrole/Nafion/functionalized multi-walled carbon nanotubes bio-nanohybrid film. J. Colloid Interface Sci. 2016, 482, 39-47. [CrossRef]

39. Chang, C.C.; Chen, C.P.; Wu, T.H.; Yang, C.H.; Lin, C.W.; Chen, C.Y. Gold Nanoparticle-Based Colorimetric Strategies for Chemical and Biological Sensing Applications. Nanomaterials 2019, 9, 861. [CrossRef]

40. Aldewachi, H.; Chalati, T.; Gardiner, P.; Woodroofe, N. Gold nanoparticle-based colorimetric biosensors. Nanoscale 2017, 10. [CrossRef] [PubMed] 